\title{
Diabetes Mellitus in Egypt: Glycaemic Control and Microvascular and Neuropathic Complications
} \author{
el Moneim el Behairy ${ }^{5}$ \\ ${ }^{1}$ University of Michigan Medical Center, Ann Arbor, Michigan, USA \\ ${ }^{2}$ Epidemiology and Statistics Branch, Division of Diabetes \\ Translation, National Center for Chronic Disease Prevention and \\ Health Promotion, Atlanta, Georgia, USA \\ ${ }^{3}$ Environmental Health Laboratory, National Center for Environmental \\ Health, Centers for Disease Control and Prevention, Atlanta, \\ Georgia, USA \\ ${ }^{4}$ Diabetes Institute, Ministry of Health, Cairo, Egypt \\ ${ }^{5}$ Central Health Laboratories, Ministry of Health, Cairo, Egypt
}

W.H. Herman*1, R.E. Aubert ${ }^{2}$, M.M. Engelgau ${ }^{2}$, T.J. Thompson ${ }^{2}$, M.A. $\mathrm{Ali}^{4}$, E.S. Sous ${ }^{4}$, M. Hegazy ${ }^{4}$ A. Badran 4 , S.J. Kenny², E.W. Gunter ${ }^{3}$, A.M. Malarcher'2, R.J. Brechner', S.F. Wetterhall2, F. DeStefano' ${ }^{2}$, P.J. Smith ${ }^{2}$, M. Habibi ${ }^{4}$, S. abd el Shakour ${ }^{4}$, A.S. Ibrahim ${ }^{4}$,

\begin{abstract}
We performed a cross-sectional, population-based survey of persons 20 years of age and older living in Cairo and surrounding rural villages. The purpose was to describe glycaemic control and the prevalence of microvascular and neuropathic complications among Egyptians with diagnosed diabetes, previously undiagnosed diabetes, impaired glucose tolerance, and normal glucose tolerance. A total of 6052 households were surveyed. The response rate was $76 \%$ for the household survey and $72 \%$ for the medical examination. Among people with previously diagnosed diabetes, mean haemoglobin $A_{1 c}$ was $9.0 \%$. Forty-two per cent had retinopathy, $21 \%$ albuminuria, and $22 \%$ neuropathy. Legal blindness was prevalent $(5 \%)$ but clinical nephropathy $(7 \%)$ and foot ulcers $(1 \%)$ were uncommon in persons with diagnosed diabetes. Among people with diagnosed diabetes, microvascular and neuropathic complications were associated with hyperglycaemia. Retinopathy was also associated with duration of diabetes; albuminuria with hypertension and hypercholesterolaemia; and neuropathy with age, female sex, and hypercholesterolaemia. Albuminuria was as common in people with previously undiagnosed diabetes $(22 \%)$ as those with diagnosed disease $(21 \%)$. Mean haemoglobin $A_{1 c}$ was lower $(7.8 \%)$ and retinopathy $(16 \%)$ and neuropathy $(14 \%)$ were less prevalent in people with previously undiagnosed disease. Ocular conditions, blindness, and neuropathy were prevalent in the non-diabetic population. The microvascular and neuropathic complications of diabetes are a major clinical and public health problem in Egypt. (c) 1998 John Wiley \& Sons, Ltd.
\end{abstract}

Diabet. Med. 15: 1045-1051 (1998)

KEY WORDS Egypt; Middle East; diabetes mellitus; epidemiology; glycosylated haemoglobin; blindness; diabetic retinopathy; diabetic nephropathy; diabetic neuropathy

Received 11 November 1997; revised 17 March 1998; accepted 27 May 1998

\section{Introduction}

During the past decade, studies on the epidemiology of diabetes mellitus have been reported from Eastern Mediterranean countries. ${ }^{1,2}$ Few have reported on the epidemiology of the complications of diabetes and none has been population-based. ${ }^{1}$ Data from clinical series have suggested that the majority of patients have

Sponsors: US Agency for International Development and the Egyptian Ministry of Health, Contract grant no.: PASA 263-0102-P-HI-1013-00 * Correspondence to: Associate Professor William Herman, University of Michigan Medical Center, 1500 E. Medical Center Drive, 3920 Taubman Center, Box 0354 Ann Arbor, MI 48109-0354 USA. E-mail: wherman@unich.edu relatively short duration of diabetes but that long-term complications occur at rates similar to those reported in Western countries. ${ }^{1}$ The purpose of this report is to describe glycaemic control and the prevalence of diabetic eye, kidney, and neuropathic complications in a population-based sample of people aged 20 years and older living in Cairo and surrounding rural villages.

\section{Patients and Methods}

The survey methods have been described previously. ${ }^{3}$ In brief, the target population for urban sampling comprised people 20 years of age and older living in Cairo, Egypt and that for rural sampling was people aged 
20 years and older living in three agricultural villages in Kaliubia, a rural delta region approximately 30 miles north of Cairo. In both urban and rural areas, trained teams of social workers visited each selected household and one person was randomly selected to participate in the study.

Each subject answered a questionnaire, underwent physical examination, and had a random capillary whole blood glucose level measured with a portable reflectance meter (One Touch II, LifeScan Inc., Milpitas, CA, USA). All respondents at high risk for diabetes (random capillary whole blood glucose $\geqslant 5.6 \mathrm{mmol} \mathrm{I}^{-1}$ ) and a random sample of those at low risk for undiagnosed diabetes (random capillary whole blood glucose $<5.6 \mathrm{mmol} \mathrm{I}^{-1}$ were invited to have a more extensive medical examination done at the Diabetes Institute in Cairo.

In the household examination, we identified 6052 eligible households. In these households, 4918 people completed the household questionnaire and 4620 completed the questionnaire and had a capillary glucose level measured (76\% response rate). On the basis of the results of the capillary glucose, 2021 people were invited to the Diabetes Institute for more detailed examination (1351 at higher risk for diabetes and a sample of 670 people at lower risk). Of those, 1451 came and completed the examination (72\% response rate). Among people at higher risk (capillary whole blood glucose levels $\geqslant 5.6 \mathrm{mmol} \mathrm{I}^{-1}$ ), the response rate was $72 \%(976 / 1351)$. Of the sample of 670 of the 3269 people at lower risk for diabetes (capillary whole blood glucose levels $<5.6 \mathrm{mmol} \mathrm{I}^{-1}$ ), 475 came and completed the medical examination ( $71 \%$ response rate).

Medical examinations were conducted by trained physicians, nurses, and technicians. All subjects provided informed consent. The examination included measurement of fasting serum glucose and serum glucose $2 \mathrm{~h}$ after a 75-g oral glucose load, haemoglobin $A_{1 c}$, urinalysis, serum creatinine, urine albumin, and urine creatinine. It also included measurement of sitting blood pressure with a mercury sphygmomanometer. An opthalmologist measured visual acuity and performed a slit lamp examination (Model M-IIB, Marco Inc., Jacksonville, FL, USA), applanation tonometry, a dilated eye examination and retinal photography through pharmacologically dilated pupils using a nonmydriatic retinal camera (CR4-45NM, Canon Inc., Tokyo, Japan). In addition a standardized foot examination and quantitative assessment of vibratory sensation using a forced choice algorithm (Vibration II, Physitemp Instruments Inc., Clifton NJ, USA) were performed. Written protocols for all procedures were developed and testing during the pilot phase of the study.

Urine dipstick testing (Chemstrip 8 urine test strips, Boehringer Mannheim Diagnostics, Indianapolis, IN, USA), serum glucose, total cholesterol, and serum creatinine measurements (Kodak Ektachem DTSCII, Eastman Kodak Co., Rochester, NY, USA) were done in the laboratory at the Diabetes Institute. Duplicate serum glucose, total cholesterol, and serum creatinine levels were measured at the Central Health Laboratories with the same methodologies. Haemoglobin $\mathrm{A}_{1 \mathrm{c}}$ was measured with affinity column chromatography (Pierce Scientific Corp., Rockford, IL, USA), urine albumin was measured by radioimmunoassay (Diagnostic Products Corp., Los Angeles, CA, USA), and urine creatinine was measured by a colorimetric Jaffe alkaline picrate method (BioMerieux, France) at the Central Health Laboratories in Cairo. Strict laboratory quality control was maintained throughout the study.

Diabetes and impaired glucose tolerance were defined according to $\mathrm{WHO}$ criteria. ${ }^{4}$ Fundus photographs were read by the Wisconsin Reading Center (Madison, WI, USA). Albuminuria was defined as an albumin-tocreatinine ratio $\geqslant 100 \mathrm{mg} \mathrm{g}^{-1}$. This level was chosen to

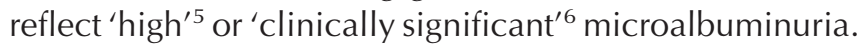
Prospective observational studies have demonstrated that subjects with a median urinary albumin excretion of approximately $100 \mathrm{mg} 24 \mathrm{~h}^{-1}$ are significantly more likely than those with lesser degrees of microalbuminuria to develop clinical nephropathy within 5 years. ${ }^{7}$ Peripheral polyneuropathy was defined empirically as a threshold for vibratory sensation $\geqslant 4 \mathrm{SD}$ above that of the non-diabetic study population 20-44 years of age. This represents individuals with vibratory sensation thresholds significantly greater than those of the young generally healthy Egyptian population. Hypertension was defined as history of hypertension or systolic blood pressure $\geqslant 160 \mathrm{mmHg}$ or diastolic blood pressure $\geqslant 95 \mathrm{mmHg}$. Data were entered in duplicate at the Diabetes Institute and analysed with EPI-Info (Centers for Disease Control and Prevention, Atlanta, GA, USA) and SAS (SAS Institute Inc., Cary, NC, USA) software.

\section{Statistical Analyses}

People were classified as having diagnosed diabetes, previously undiagnosed diabetes, impaired glucose tolerance, or normal glucose tolerance on the basis of their histories of diabetes and the results of the oral glucose tolerance tests. The population was treated as an unweighted cross-sectional cohort. In Tables 1-4 both means and $95 \%$ confidence intervals $(95 \% \mathrm{Cl})$ are presented. Logistic regression models were used to assess variables independently associated with diabetic retinopathy, albuminuria, and neuropathy in people with diagnosed diabetes. Explanatory variables included age, duration of diabetes, sex, socio-economic status (SES) and residence (upper SES and urban residence, lower SES and urban residence, and rural residence), haemoglobin $A_{1 c}$, hypertension, hypercholesterolaemia, and cigarette smoking. Results are presented as odds ratios $(\mathrm{OR})$ and $95 \%$ confidence intervals.

\section{Results}

People with abnormal glucose tolerance were older and more likely to be female than those with normal glucose 
tolerance. Of those with diagnosed diabetes, $83 \%$ were $\geqslant 45$ years of age and $65 \%$ were female. Of those with previously undiagnosed diabetes, $77 \%$ were $\geqslant 45$ years of age and $69 \%$ were female. Of people with IGT, $54 \%$ were $\geqslant 45$ years of age and $59 \%$ were female. Of those with normal glucose tolerance, $44 \%$ were $\geqslant 45$ years of age and $57 \%$ were female.

Haemoglobin $\mathrm{A}_{1 \mathrm{c}}$ levels were higher among people with diagnosed diabetes than among those with previously undiagnosed diabetes (Table 1). Mean haemoglobin $\mathrm{A}_{1 \mathrm{c}}$ levels were $9.3 \%$ in those with insulin-treated diabetes and $8.9 \%$ among people with diagnosed diabetes not treated with insulin. Among people with diabetes, haemoglobin $A_{1 c}$ levels tended to decrease with age. Haemoglobin $A_{1 c}$ levels were not different between the groups with IGT and normal glucose tolerance and tended to increase slightly with age.

Legal blindness (defined as best corrected visual acuity in the better eye <6/60) was present in $5 \%$ of those with diagnosed diabetes and diabetic retinopathy was present in $42 \%$ (Table 2 ). In multivariate analysis using logistic regression, diabetic retinopathy was associated with longer duration of diabetes (per 10 years) $(\mathrm{OR}=$ $1.37,95 \% \mathrm{Cl} 1.09,1.73)$ and higher haemoglobin $\mathrm{A}_{1 \mathrm{c}}$ (per unit) $(\mathrm{OR}=1.15,95 \% \mathrm{Cl} 1.03,1.27)$. Corneal disease (defined as any central or peripheral nebula or leukoma) was prevalent in all groups (Table 2). Cataract (defined as any nuclear or cortical cataract) and intraocular hypertension (defined as intraocular pressure $>21 \mathrm{mmHg}$ in either eye) were more prevalent in people with diabetes than in those with IGT or normal glucose tolerance (Table 2). Compared to people without diabetes, the relative risks of both cataract and intraocular hypertension were greater among younger people with diabetes. Sixty-two per cent of people with diagnosed diabetes, $47 \%$ of those with previously undiagnosed diabetes, $27 \%$ of those with IGT, and $22 \%$ of those with normal glucose tolerance had evidence of the eye diseases assessed in this study (Table 2).

Albuminuria, defined as an albumin-to-creatinine ratio of $\geqslant 100 \mathrm{mg} \mathrm{g}$-creatinine $^{-1}$ in the presence of $<10$ red blood cells per high-powered field and no leukocytes on dipstick testing, was more prevalent in people with diagnosed and undiagnosed diabetes than in those with IGT and normal glucose tolerance (Table 3). The prevalence of albuminuria was $25 \%$ among people with diabetes and hypertension (history of hypertension and/or systolic $B P \geqslant 160$ and/or diastolic BP $\geqslant 95 \mathrm{mmHg}$ ), $20 \%$ among people with hypertension only, $17 \%$ among people with diabetes only, and $5 \%$ among people with neither diabetes nor hypertension. In multivariate analysis, albuminuria was associated with hypertension $(\mathrm{OR}=$ $2.72,95 \% \mathrm{Cl} 1.21,6.11$ ), higher haemoglobin $\mathrm{A}_{1 \mathrm{c}}$ (per unit) $(\mathrm{OR}=1.15,95 \% \mathrm{Cl} 0.99,1.34)$, and higher total cholesterol (per 0.26 unit) $(\mathrm{OR}=1.04,95 \% \mathrm{Cl} 1.00$, 1.09). Clinical nephropathy, defined as an albumin-tocreatinine ratio of $\geqslant 300 \mathrm{mg}$ g-creatinine ${ }^{-1}$, was present in $7 \%$ of those with diagnosed and undiagnosed diabetes and was approximately four times as prevalent in people with diabetes as in those with IGT and normal glucose tolerance (Table 3). Very few subjects had evidence of renal insufficiency (serum creatinine $\geqslant 180 \mu \mathrm{mol} \mathrm{I}{ }^{-1}$ ).

Peripheral polyneuropathy, defined as a threshold for vibratory sensation $\geqslant 4$ SD above that of the non-diabetic population 20-44 years of age, was more common in people with diabetes, and the prevalence increased with age (Table 4). In multivariate analysis, neuropathy was associated with older age (per 10 years) $(\mathrm{OR}=2.01$, $95 \% \mathrm{Cl} 1.43,2.82)$, female sex $(\mathrm{OR}=2.34,95 \% \mathrm{Cl}$ 1.17 , 4.69), higher haemoglobin $A_{1 c}$ (per unit) $(O R=$ $1.14,95 \% \mathrm{Cl} 1.02,1.28)$, and higher total cholesterol (per 0.26 unit) $(\mathrm{OR}=1.04,95 \% \mathrm{Cl} 1.00,1.08)$. Peripheral polyneuropathy was also common in older people without diabetes. Foot ulcers were present in less than $1 \%$ of subjects but were more prevalent in people with diabetes than in those without (Table 4).

\section{Discussion}

We report cross-sectional population-based data on glycaemic control and the prevalence of microvascular and neuropathic complications and their risk factors among Egyptians with diabetes mellitus, previously undiagnosed diabetes mellitus, impaired glucose tolerance, and normal glucose tolerance. To our knowledge, such population-based data have not been reported previously from the Eastern Mediterranean Region.

Our finding that haemoglobin $\mathrm{A}_{1 \mathrm{c}}$ was highest among subjects with diagnosed diabetes, higher than among those with previously undiagnosed diabetes, probably reflects the more severe hyperglycaemia of the former. Our finding of higher haemoglobin $A_{1 c}$ levels in younger

Table 1. Mean haemoglobin $A_{1 c}$ levels and $95 \%$ confidence interval by age and diabetes status

\begin{tabular}{|c|c|c|c|c|}
\hline Age & $\begin{array}{c}\text { DxDM } \\
(n=364) \\
\mathrm{A}_{1 \mathrm{c}} \%(\mathrm{Cl})\end{array}$ & $\begin{array}{l}\text { UndxDM } \\
(n=114) \\
\mathrm{A}_{1 \mathrm{c}} \%(\mathrm{Cl})\end{array}$ & $\begin{array}{c}\text { IGT } \\
(n=127) \\
\mathrm{A}_{1 \mathrm{c}} \%(\mathrm{Cl})\end{array}$ & $\begin{array}{c}\text { Normal } \\
(n=697) \\
\mathrm{A}_{1 \mathrm{c}} \%(\mathrm{Cl})\end{array}$ \\
\hline \multicolumn{5}{|l|}{$\mathrm{HbA}_{1 \mathrm{c}}$} \\
\hline $20-44$ & $9.2(8.5,9.9)$ & $8.4(7.5,9.3)$ & $5.4(5.2,5.7)$ & $5.3(5.2,5.4)$ \\
\hline $45+$ & $9.0(9.7,9.2)$ & $7.7(7.3,8.1)$ & $5.5(5.4,5.7)$ & $5.4(5.3,5.6)$ \\
\hline Total & $9.0(8.7,9.2)$ & $7.8(7.5,8.2)$ & $5.5(5.3,5.6)$ & $5.4(5.3,5.4)$ \\
\hline
\end{tabular}

$\mathrm{Cl}, 95 \%$ confidence interval; DxDM, diagnosed diabetes; UndxDM; previously undiagnosed diabetes. 
Table 2. Prevalence of legal blindness, retinopathy, corneal opacity, cataract, intraocular hypertension, and any eye disease, and $95 \%$ confidence intervals by age and diabetes status

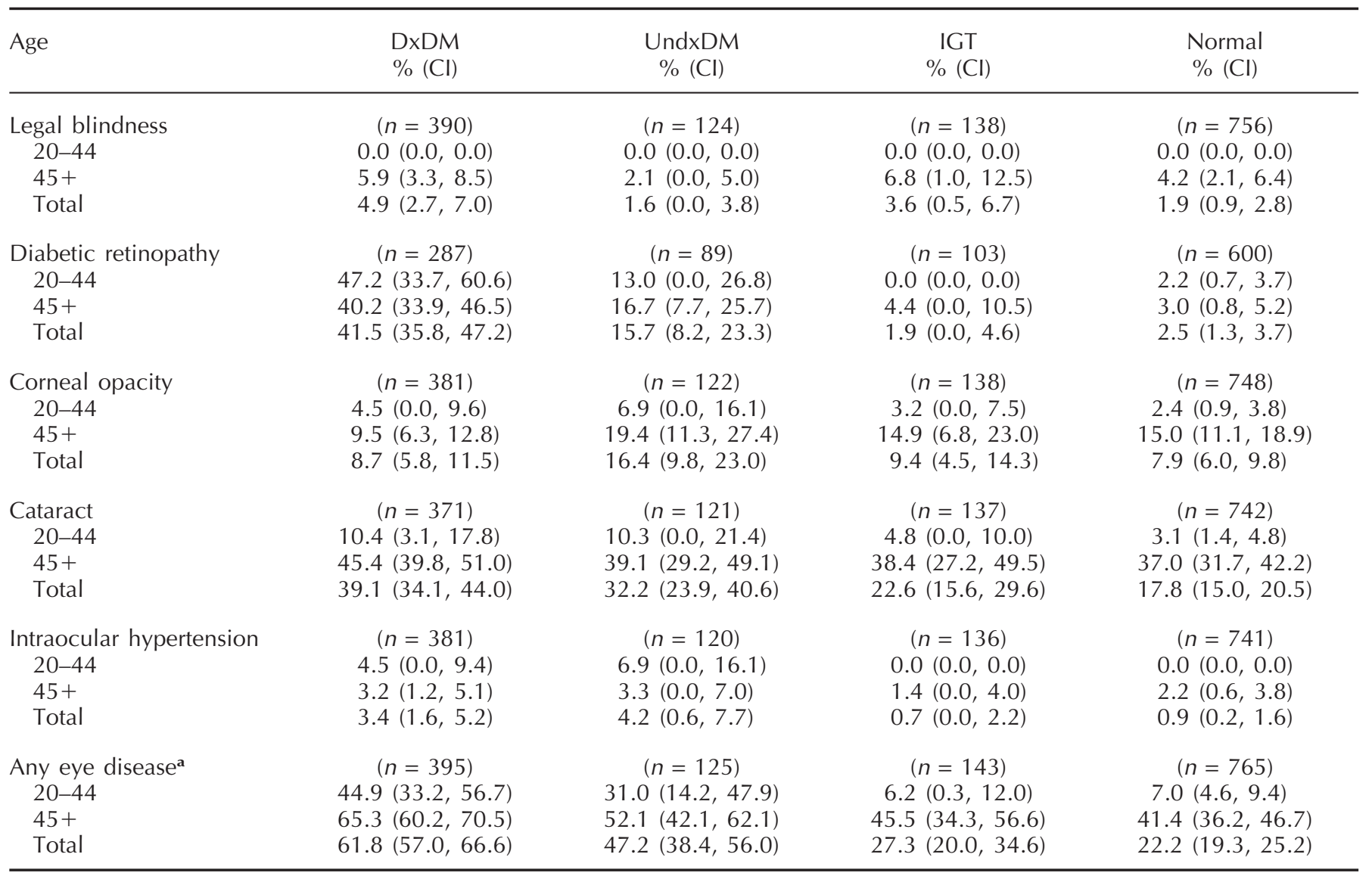

aAny disorder noted in table.

$\mathrm{Cl}, 95 \%$ confidence interval; DxDM, diagnosed diabetes; UndxDM, previously undiagnosed diabetes.

Table 3. Prevalence of albuminuria and clinical nephropathy, and $95 \%$ confidence intervals by age and diabetes status

\begin{tabular}{lcccc}
\hline Age & $\begin{array}{c}\text { DxDM } \\
\%(\mathrm{Cl})\end{array}$ & $\begin{array}{c}\text { UndxDM } \\
\%(\mathrm{Cl})\end{array}$ & $\begin{array}{c}\text { IGT } \\
\%(\mathrm{Cl})\end{array}$ & $\begin{array}{c}\text { Normal } \\
\%(\mathrm{Cl})\end{array}$ \\
\hline $\begin{array}{l}\text { Albuminuria } \\
20-44\end{array}$ & $(n=210)$ & $(n=73)$ & $(n=61)$ & $(n=389)$ \\
$\quad 45+$ & $24.2(9.6,38.9)$ & $12.5(0.0,28.7)$ & $8.3(0.0,19.4)$ & $6.3(3.1,9.5)$ \\
$\quad \begin{array}{l}\text { Total } \\
\text { Clinical nephropathy }\end{array}$ & $20.3(14.4,26.3)$ & $24.6(13.4,35.7)$ & $13.9(2.6,25.2)$ & $11.4(6.6,16.3)$ \\
$\quad$ Total & $21.0(15.4,26.5)$ & $21.9(12.4,31.4)$ & $11.5(3.5,19.5)$ & $8.5(5.7,11.3)$ \\
\hline
\end{tabular}

aUrine albumin: creatinine ratio $\geqslant 100 \mathrm{mg} \mathrm{g}^{-1}$

burine albumin: creatinine ratio $\geqslant 300 \mathrm{mg} \mathrm{g}^{-1}$

$\mathrm{Cl}, 95 \%$ confidence interval; DxDM, diagnosed diabetes; UndxDM, previously undiagnosed diabetes.

people with diagnosed and undiagnosed diabetes probably reflects the admixture of people with Type 1 and Type 2 diabetes, with more Type 1 disease in the younger group. ${ }^{8}$ Blood glucose control in the Egyptian population with diagnosed diabetes was similar to that observed among conventionally treated subjects in the Diabetes Control and Complications Trial. $^{9}$ Our haemoglobin $\mathrm{A}_{1 \mathrm{c}}$ findings are consistent with epidemiologic studies that have reported fasting glucose levels. ${ }^{10}$
The prevalence of legal blindness in all our subjects, as has been reported in other populations, increased with age. In the Wisconsin Epidemiologic Study of Diabetic Retinopathy (WESDR), Klein estimated that $2 \%$ of people with Type 2 diabetes were blind ${ }^{11}$ and in a study from Poole, Houston estimated that $1 \%$ of insulintaking diabetic people and $2 \%$ of non-insulin-taking diabetic people were legally blind. ${ }^{12}$ The high prevalence of legal blindness in the Egyptian population, including 
Table 4. Prevalence of peripheral polyneuropathy and foot ulcers, and $95 \%$ confidence intervals by age and diabetes status

\begin{tabular}{|c|c|c|c|c|}
\hline Age & $\begin{array}{l}\text { DxDM } \\
\%(\mathrm{Cl})\end{array}$ & $\begin{array}{l}\text { UndxDM } \\
\%(\mathrm{Cl})\end{array}$ & $\begin{array}{c}\text { IGT } \\
\%(\mathrm{Cl})\end{array}$ & $\begin{array}{l}\text { Normal } \\
\%(\mathrm{Cl})\end{array}$ \\
\hline Neuropathy ${ }^{\mathbf{a}}$ & $(n=384)$ & $(n=125)$ & $(n=140)$ & $(n=750)$ \\
\hline 20-44 & $11.8(4.1,19.4)$ & $0.0(0.0,0.0)$ & $1.6(0.0,4.7)$ & $0.5(0.0,1.1)$ \\
\hline $45+$ & $24.1(19.3,28.8)$ & $17.7(10.1,25.3)$ & $17.1(8.6,25.6)$ & $13.4(9.7,17.1)$ \\
\hline Total & $21.9(17.7,26.0)$ & $13.6(7.6,19.6)$ & $10.0(5.0,15.0)$ & $6.1(4.4,7.9)$ \\
\hline Foot ulcers & $(n=389)$ & $(n=123)$ & $(n=140)$ & $(n=753)$ \\
\hline Total & $0.8(0.0,1.6)$ & $0.8(0.0,2.4)$ & $0.0(0.0,0.0)$ & $0.1(0.4,0.4)$ \\
\hline
\end{tabular}

aDefined as Vibratron reading $\geqslant 4$ SD above that for the normal population 20-44 years of age.

$\mathrm{Cl}, 95 \%$ confidence interval; DxDM, diagnosed diabetes; UndxDM, previously undiagnosed diabetes.

non-diabetic groups, probably reflects a greater prevalence of other conditions associated with visual impairment and, possibly, less access to eye care.

Using retinal photography as a criterion for diagnosing diabetic retinopathy, we found that $42 \%$ of subjects with diagnosed diabetes and $16 \%$ of subjects with previously undiagnosed diabetes had diabetic retinopathy. Among those with diagnosed diabetes, retinopathy was associated with duration of diabetes and hyperglycaemia. The rates of retinopathy are quite similar to the crude prevalence rates of diabetic retinopathy found in other epidemiologic studies that have employed fundus photography. ${ }^{13-17}$ Our finding that $16 \%$ of those with previously undiagnosed diabetes had diabetic retinopathy suggests that the duration of diabetes before clinical diagnosis was approximately 8 years. ${ }^{18}$ In other populations with previously undiagnosed diabetes, the duration of diabetes before clinical diagnosis has been reported to be 9 to 12 years. ${ }^{19}$ These data suggest that in Egypt the severity of hyperglycaemia is less or the duration of diabetes from onset to diagnosis is shorter than in rural Australia or southern Wisconsin. Low measurable rates of diabetic retinopathy in the Egyptian populations with impaired glucose tolerance and normal glucose tolerance may reflect misclassification of drusen or hypertensive retinopathy, misclassification of diabetes status, or regression of diabetes towards normal glucose tolerance.

We found a high prevalence of corneal disease which appeared to be non-differentially distributed among diabetic and non-diabetic subjects. This is likely to be due to a high prevalence of traumatic injury and trachoma in the population. There have been few previous studies of corneal problems in persons with diabetes. In the Beaver Dam Eye Study (Wisconsin, USA), there was no difference between people with and without diabetes in regards to corneal abnormalities. ${ }^{11}$ Previous clinic-based studies of Type 1 diabetic subjects have, however, indicated a higher prevalence of subtle corneal changes. ${ }^{20,21}$

Cataracts were common in all our subjects (albeit more common in the diabetic groups) and the prevalence increased with age. This prevalence is lower than observed in Wisconsin where approximately $27 \%$ of subjects with Type 1 diabetes and $86 \%$ of subjects with
Type 2 diabetes had cataracts. ${ }^{11}$ This may be due to the younger age distribution of the population. Ascertainment bias may have also contributed to the difference.

Our glaucoma rates in the diabetic $(4 \%)$ and nondiabetic $(1 \%)$ groups were similar to those reported in other population-based studies. ${ }^{11}$

Microalbuminuria was prevalent in our diabetic subjects and low levels (30-99 $\mathrm{mg} \mathrm{g}^{-1}$ ) were prevalent in the entire population regardless of glucose tolerance (data not shown). These findings are consistent with a Saudi Arabian clinic-based study in which $42 \%$ of diabetic subjects and $13 \%$ of non-diabetic controls had microalbuminuria but fewer than $10 \%$ of diabetic subjects and none of the non-diabetic subjects had urinary albumin excretion rates greater than $100 \mathrm{mg}$ $24 \mathrm{~h}^{-1} .^{22}$ This suggests that factors transiently increase albuminuria such as uncontrolled hypertension or exercise may be prevalent in the populations with and without diabetes. ${ }^{23}$ Rates of albuminuria (urine albuminto-creatinine ratio $\geqslant 100 \mathrm{mg} \mathrm{g}^{-1}$ ) were not different between groups with diagnosed and undiagnosed diabetes, approximately twice as high as in non-diabetic subjects. Among people with diagnosed diabetes, albuminuria was associated with hypertension, hypercholesterolaemia and hyperglycaemia. The role of hypertension is underscored by the fact that the prevalence of albuminuria was highest among persons with diabetes and hypertension, essentially the same among persons with hypertension only and persons with diabetes only, and lowest among persons with neither diabetes nor hypertension.

We found that the prevalence of clinical nephropathy $(7 \%)$ was three-fold higher than in subjects without diabetes $(2 \%)$ but was two- to three-times lower than the crude prevalence of clinical nephropathy in the Saudi Arabian clinic-based study $(13 \%)^{22}$ and three-fold lower than observed in southern Wisconsin $(21 \%){ }^{24}$ The reason for these differences is not clear. The higher prevalence of clinical nephropathy in diabetic subjects in Saudi Arabia may reflect selection bias associated with a clinic-based study. The higher prevalence of clinical nephropathy in diabetic subjects in Wisconsin may reflect differences in the distributions of age, duration, and severity of diabetes. Decreased genetic susceptibility to nephropathy or decreased survival of 
subjects with nephropathy in Egypt might also explain these differences.

Twenty-two per cent of our subjects with diagnosed diabetes had distal symmetrical sensorimotor polyneuropathy based on quantitative vibration perception testing. Among people with diagnosed diabetes, neuropathy was associated with older age, female sex, hyperglycaemia, and hypercholesterolemia. Recent cross-sectional studies have provided population-based estimates of the frequency of diabetic neuropathy ranging from $16 \%$ to $42 \%{ }^{25-28}$ Our finding of an intermediate prevalence of polyneuropathy in the population with undiagnosed diabetes suggests that diabetes has existed for some time before clinical diagnosis. The prevalence of neuropathy of $6 \%$ in the non-diabetic population may represent neuropathy due to other causes. ${ }^{29}$

The prevalence of foot ulcers was low in our diabetic population. In British population-based studies, the prevalence of current diabetic foot ulcers on examination ranges from $1 \%$ to $3 \% .{ }^{26,30}$ Differences in the distributions of age, duration, and severity of diabetes between the populations, differences in the prevalence or severity of neuropathy, increased attention to care of the foot associated with Egyptian cultural practices, or decreased survival of subjects with foot ulcers in Egypt might explain these differences.

In summary, our data are consistent with those of population-based studies from around the world and confirm that diabetes and its complications are now major clinical and public health problems in Egypt. There are, however, intriguing differences including a relatively low prevalence of clinical nephropathy and foot ulcers in the diabetic population and a high prevalence of other ocular conditions, blindness, and peripheral polyneuropathy in the Egyptian population without diabetes. These warrant further exploration.

\section{Acknowledgements}

This study was supported by the US Agency for International Development and the Egyptian Ministry of Health under PASA 263-0102-P-HI-1013-00. The authors wish to acknowledge the work and dedication of the following persons, whose contributions made this project possible: E. el Gannam, R.B. Eskander, M.A. Sustanos, T. Naser, G. Boulis, A.A. el Maguid, K. Darwish, M. Gaad, M.S. Ibrahim, M. Aziz, T. el Bassioni, M. Shaltot, S. Khairy, D. Attia, A. el Kousy, N. abd el Magid, A. Saad Eldin, I. Hussein, A. el Erian, M.H. el Nagar, A.M. abou el Saad, M. abd el Masyeh, S. abel Shafi, M.J. Ostrowski, D.B. Bertram, J.L. Clayton, M.A. Montalbano, C. Stewart, M. Neider, E.J. Belansky, R. Walling, M. Kefauver, C.W. Richardson, N.B. Loner, G.D. Goolsby, and N.L. Fink.

\section{References}

1. WHO/EM/dia/3/E/G Diabetes Prevention and control. A call for action. Alexandria, Egypt: World Health Organization Regional Office for the Eastern Mediterranean, 1993.

2. Alwan A. Noncommunicable diseases: a major challenge to public health in the region. Eastern Mediterranean Hlth J 1997; 3: 6-16.

3. Herman $W H$, Ali MA, Aubert RE, Engelgau MM, Kenny SJ, Gunter EW, et al. Diabetes mellitus in Egypt risk factors and prevalence. Diabetic Med 1995; 12: 1126-1131.

4. Laffel LBM, Warram JH, Krolewski AS. Glycemic control does not predict progression from low to high microalbuminuria in insulin-dependent diabetes mellitus (IDDM) (Abstract). J Am Soc Nephrol 1994; 5: 379.

5. Siegel JE, Krolewski AS, Warram JH, Weinstein MC. Cost-effectiveness of screening and early treatment of nephropathy in patients with insulin-dependent diabetes mellitus. J Am Soc Nephrol 1992; 3: (suppl 1): S111-S119.

6. Almdal T, Nörgaard K, Feldt-Rasmussen B, Deckert T. The predictive value of microalbuminuria in IDDM. Diabetes Care 1994; 17: 120-125.

7. World Health Organization: Diabetes Mellitus. Report of a WHO Study Group. Technical Report Series No. 727. Geneva: WHO, 1985.

8. Klein R. Hyperglycemia and microvascular and macrovascular disease in diabetes. Diabetes Care 1995; 18: 258-268.

9. The Diabetes Control and Complications Trial Research Group. The effect of intensive treatment of diabetes on the development and progression of long-term complications in insulin-dependent diabetes mellitus. New Engl J Med 1993; 329: 977-986.

10. Cowie CC, Harris MI. Physical and metabolic characteristics of persons with diabetes. In: National Diabetes Data Group, eds., Diabetes in America, 2nd edn. National Institutes of Health, National Institute of Diabetes and Digestive and Kidney Diseases, NIH Publication No. 951468. 1995: 117-133.

11. Klein R, Klein BEK. Vision disorders in diabetes. In: National Diabetes Data Group, eds. Diabetes in America, 2nd edn. National Institutes of Health, National Institute of Diabetes and Digestive Kidney Diseases, NIH Publication No. 95-1468. 1995: 293-338.

12. Houston A. Retinopathy in the Poole area: An epidemiological inquiry. In: Eschwege E, ed. Advances in Diabetes Epidemiology. Amsterdam: Elsevier, 1982.

13. Constable IJ, Knuiman MW, Welborn TA, Cooper RL, Stanton KM, McCann VJ, Grose GC. Assessing the risk of diabetic retinopathy. Am J Ophthalmol 1984; 97: 53-61.

14. Ross SA. Huchcroft SA. Hyperlipidemia and vascular risk factors among diabetics in southern Alberta. Clin Invest Med 1989; 12: B25.

15. Nielsen NV. Diabetic retinopathy. I. The course of retinopathy in insulin-treated diabetics. A one-year epidemiologic cohort study of diabetes mellitus. The Island of Flaster, Denmark. Acta Ophthalmol 1984; 62: 256-265.

16. Nielsen NV. Diabetic retinopathy. II. The course of retinopathy in diabetics treated with oral hypoglycemic agents and diet regime alone. A one-year epidemiologic cohort study of diabetes mellitus. The Island of Flaster, Denmark. Acta Ophthalmol 1984; 62: 266-273.

17. Haffner SM, Fond D, Stern MP, Pugh JA, Hazuda HP, Patterson JK, et al. Diabetic retinopathy in Mexican Americans and non-Hispanic whites. Diabetes 1988; 37: 878-884.

18. Thompson TJ, Engelgau MM, Hegazy M, Ali MA, Sous 


\section{INTERNATIONAL SCENE}

ES, Badran A, Herman WH. The onset of NIDDM and its relationship to clinical diagnosis in Egyptian adults. Diabetic Med 1996; 13: 337-340.

19. Harris MI, Klein R, Welborn TA, Knuiman MW. Onset of NIDDM occurs at least 4-7 years before clinical diagnosis. Diabetes Care 1992; 15: 815-819.

20. Busted N, Olsen T, Schmitz O. Clinical observation on the corneal thickness and corneal endothelium in diabetes mellitus. Br J Ophthalmol 1981; 65: 687-690.

21. Schultz RO, VanHorn DL, Peters MA, et al. Diabetic keratopathy. Trans Am Ophthalmol Soc 1981; 79: 180199.

22. Alzaid AA, Sobki S, De Silva V. Prevalence of microalbuminuria in Saudi Arabians with non-insulin-dependent diabetes mellitus: a clinic-based study. Diabetes Res Clin Pract 1994; 26: 115-120.

23. American Diabetes Association. Consensus development conference on the diagnosis and management of nephropathy in patients with diabetes mellitus. Diabetes Care 1994; 17: 1357-1361.

24. Klein R, Klein BEK, Moss SE. Prevalence of microalbuminuria in older-onset diabetes. Diabetes Care 1993; 16: 1325-1330.
25. Walters DP, Gatling W, Mullee MA, Hill RD. The prevalence of diabetic distal sensory neuropathy in an English Community. Diabetic Med 1992; 9: 349-353.

26. Kumar S, Ashe HA, Parnell LN, Fernando DJS, Tsigos C, Young RJ, et al. The prevalence of foot ulceration and its correlates in type 2 diabetic patients: a population-based study. Diabetic Med 1994; 11: 480-484.

27. Dyck PJ, Kratz KM, Lehman KA, Karnes JL, Melton III JL, O'Brien PC, et al. The Rochester Diabetic Neuropathy Study. Neurology 1991; 41: 799-807.

28. Franklin GM, Kahn LB, Baxter J, Marshall JA, Hamman RF. Sensory neuropathy in non-insulin-dependent diabetes mellitus: The San Luis Valley Diabetes Study. Am J Epidemiol 1990; 131: 633-643.

29. Herman $\mathbf{W H}$, Greene DA. Microvascular complications of diabetes. In: Haire-Joshu, ed. Management of Diabetes Mellitus, 2nd edn. St Louis, MO: Mosby-Year Book, 1996: 234-280.

30. Walters DP, Gatling W, Mullee MA, Hill RD. The distribution and severity of diabetic foot disease: a community study with comparison to a non-diabetic group. Diabetic Med 1992; 9: 354-358. 